\title{
Modeling and Control Simulation of a Robotic Chair-Arm: Protection against COVID-19 in Rehabilitation Exercise
}

\author{
M. Akhtaruzzaman 1*, Amir A. Shafie' ${ }^{2}$, Md Raisuddin Khan ${ }^{3}$, and Md Mozasser Rahman ${ }^{4}$ \\ 1 Dept. of Computer Science and Engineering, Military Institute of Science and Technology (MIST), Dhaka, Bangladesh \\ 2,3 Dept. of Mechatronics Engineering, International Islamic University Malaysia (IIUM), 53100 Kuala Lumpur, Malaysia \\ ${ }^{4}$ Dept. of Mechanical Engineering Technology, Universiti Tun Hussein Onn Malaysia (UTHM), 84600 Pagoh, Johor, Malaysia \\ ${ }^{1}$ R\&D (Robotics) Section, DREAM Robotics Ltd., Dhaka, Bangladesh \\ emails: ${ }^{* 1}$ akhter900@cse.mist.ac.bd; ${ }^{2} a a s h a f i e @ i i u m . e d u . m y ;{ }^{3}$ raisuddin@iium.edu.my; and ${ }^{4}$ mozasser@uthm.edu.my
}

\section{ART ICLE INFO}

Article History:

Received: $18^{\text {th }}$ July 2020

Revised: $10^{\text {th }}$ September 2020

Accepted: $11^{\text {th }}$ October 2020

Published: $16^{\text {th }}$ December 2020

Keywords:

1-DoF robotic arm Robotic chair-arm

Robot-assisted rehabilitation

Lower-limbs therapeutic exercise

Robot-assisted system

COVID-19

\begin{abstract}
A B S T R A C T
In the field of rehabilitation, lower-limbs therapeutic exercise has become a challenging job for medical professionals in COVID-19 pandemic. Providing manual therapy to lower limbs is not an easy task and, in most cases, it involves multiple persons. Moreover, it is a monotonous job, and the service providers need to be in close contact with the patient thereby creating the risk of infection. In this circumstance, robot-assisted rehabilitation exercise for lower limbs offers a risk-free solution. This paper presents dynamic modeling and control simulation of One Degree of Freedom robotic chair-arm (robotic arm attached with a special chair). The control structure is designed with two compensators for position and velocity control. The simulation results show that the proposed system has a good potential in providing automatic rehabilitation therapy for lower limbs, especially for knee joint range of motion exercise. The results also indicate faster responses with settling time less than 0.04 second and steady-state error below 0.05 . The findings show that a robotic chair arm can be used for providing automatic therapy to patients in situations like COVID-19 pandemic.
\end{abstract}

\section{INTRODUCTION}

The COVID-19 has become an epidemic throughout the world which has been forcing humanity to be demobilized by creating intangible obstacles and threats to fulfill our five basic needs, foods, clothing, shelter, healthcare, and education. Healthcare and education sectors are dangerously affected by the invasion of Corona Virus. COVID-19 is highly contagious which makes medical services difficult to provide. Clinical care service is one of the broad areas where robotics can contribute to change the sector to reach its highest level (Yang et al., 2020; Zeng, Chen, \& Lew, 2020).

Global demand for rehabilitation services is increasing because of growing non-communicable diseases like stroke and heart attacks. Moreover, the current situation of the global pandemic raises greater demand for robot-assisted rehabilitation systems in minimizing the risk of contamination both for healthcare service providers and patients (Zeng, Chen, \& Lew, 2020; Kimmig et al., 2020). To increase Range of Motion (RoM) flexibility of knee joint and motor neuron dysfunction, continuous passive
RoM exercise is a monotonous and arduous job in terms of physical labor and time. Repeated manual exercise also unable to comply with natural motion patterns during the whole exercise session. Furthermore, transporting the patient for each session increases time overheads, cost, and discomfort to the patients. Thus, to decrease the burden, design and control simulation of a 1-DoF robotic arm for knee RoM exercise is presented in this manuscript. The arm is attached with a special chair so that a disabled patient can be seated on to receive knee joint RoM therapeutic exercise.

Robot-assisted rehabilitation exercise for functional adaptation of knee joint RoM widens a great opportunity for post-stroke patients (Akhtaruzzaman et al., 2019). Robot-assisted system also could be a great tool to measure functional improvements of muscles and joint motions (Huang et al., 2019). The instrumentation system of a robotic arm can perform precise measurement of positions and forces and able to co-operate with human (Shi et al., 2019). More importantly, electro-mechanical actuators of the system can perform a task repeatedly within the desired 
workspace of a joint (Hussain, Xie, \& Jamwal, 2013; Lee et al., 2016; Shi et al., 2019).

NeXOS was introduced by Bradley et al. (2009) as a 2DoF automated system to perform active assistive as well as passive and resistive therapeutic exercises. Pre-trained visual trajectory and position information were implemented to make the system reliable for hip and knee extension-flexion exercise. Targeted users of the system were the stroke patients for post-stroke rehabilitation exercise. A robot-assisted system, Multi-Iso, was designed for knee extension-flexion exercise by Moughamir et al. (2002) that can provide assistive rehabilitation along with passive and resistive therapeutic exercises. A fuzzy intelligent control strategy was introduced in the system where sequence control mechanisms of position, velocity, and force were considered. For the treatment of Crouch gait, a powered exoskeleton system was designed to comply with the kinematic structure of knee, ankle, and foot (Lerner et al., 2016). The robotic exoskeleton system was able to aid with knee-extension during gait training for adults and children.

Though the position-velocity control is not sufficient, it is the initial step for designing a robot assistive system. This paper describes the initial stage of a robot-assisted system for knee joint RoM rehabilitation exercise, thus presents dynamic modeling and position-velocity control simulation of the system. Newtonian dynamic analysis is adopted to determine the necessary equations. The control architecture is designed with two compensators based on ProportionalDerivative-Integral (PID) tuning method. Simulation results have confirmed the suitability of the proposed mechatronics system for its potential applications and improvements.

\section{SYSTEM DESIGN AND MODELING}

\section{A. Mechanical Design and Component Selection}

The system is designed so that a patient can be seated on the seat-mount while adjusting knee joint axes to be cocentric with the primary and secondary shaft rotational axis. Figure 1 presents the left view of the robot-assisted system as designed for knee joint RoM rehabilitation exercise.

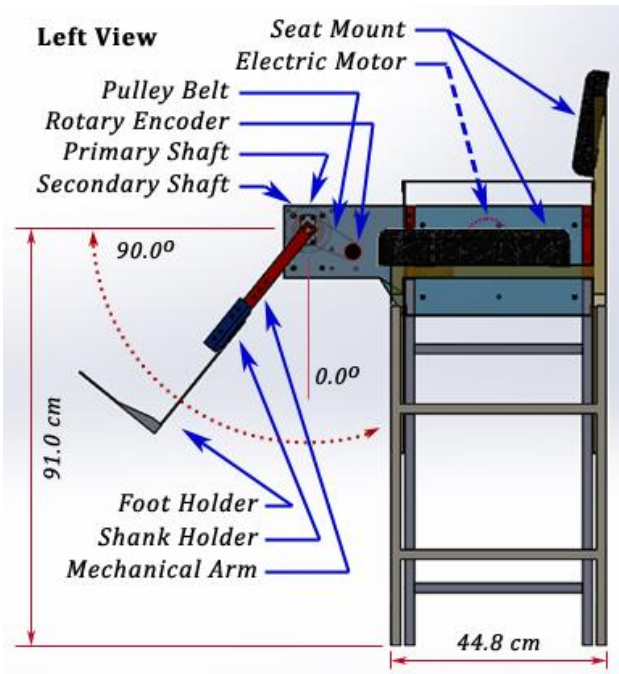

Figure 1: A Robotic Arm with a mechanical chair (Left View)
The robotic arm (mechanical arm) will be attached with the shank of the patient leg at the shank holder position and the foot will be attached with the foot holder of the system. The height of the knee joint axis is $91.0 \mathrm{~cm}$ enabling enough space for knee RoM exercise within the motion range from flexion to extension (Akhtaruzzaman et al., 2019). For modeling and simulation, presented in this paper, $90.0^{\circ}$ flexion of the knee is considered as a start $\left(0.0^{\circ}\right)$ and $0.0^{\circ}$ extension of the knee is considered as end $\left(90.0^{\circ}\right)$ positions of robotic arm motion range. For prototype development, aluminum sheet-metal can be chosen (Abdezadeh et al., 2016) to develop the extended structure of the chair.

The design focuses only on the right knee for experimental purposes and can be upgraded by applying the same mechanism at the left side of the chair to provide therapeutic exercise to the left knee. The mechanical and electro-mechanical components attached to the system prototype are DC Motor (SPG S8D40-24A with gearhead

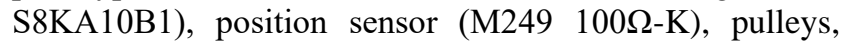
pulley belts, primary shaft, secondary shaft, rotary encoder (3806-500B-5-24F), and coupling. Electronics and control circuit of the rehabilitation system consists of a customdesigned latch module, relay module, motor driver (L298N H-Bridge), two $\mu$-controllers (Arduino-Mega, master \& slave), switch \& connection module, ethernet module, and custom-designed multiport power-supply unit. A designed control algorithm is implemented in Arduino-Mega.

\section{B. Determining System Torque}

The free-body diagram of the proposed mechatronics system is presented in Figure 2. Based on the general equation of torque $(\tau=I \alpha)$, formula of the system actuator torque $\left(\tau_{M}\right)$ is presented in Equation (1). Here, $I$ is the rotational inertia and $\alpha$ is the angular acceleration. To determine the value of the Primary and Secondary Shafts angular acceleration $\left(\alpha_{S}\right)$, the time of one revolution is chosen as 24 seconds. So, revolution per minute $(R P M)$ can be calculated as $(R P M=$ $(1 * 60) / 24=2.5 \mathrm{rev} / \mathrm{min})$. Thus, angular acceleration $\left(\alpha_{S}\right)$ can be calculated as, $\alpha_{S}=\omega_{S} / t_{S}=0.13 \mathrm{rad} / \mathrm{sec}^{2}$. Here, angular velocity, $\omega_{S}=(2.5 * 2 \pi) / 60 \mathrm{rad} / \mathrm{sec}$, and time for $30^{\circ}$ rotation, $t_{S}=2 \mathrm{sec}$.

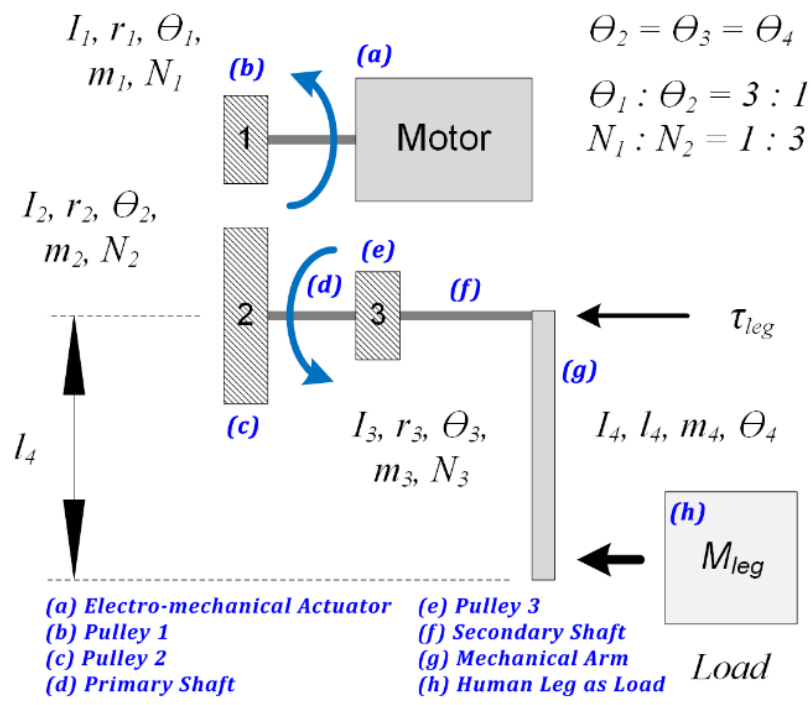

Figure 2: Free-body diagram of the mechatronics system 


$$
\tau_{M}=\begin{aligned}
& \frac{1}{2} m_{1} r_{1}^{2} \alpha_{1}+ \\
& \left(\frac{N_{1}}{N_{2}}\right)^{2}\left\{\alpha_{S}\left(\frac{1}{2}\left(m_{2} r_{2}^{2}+m_{3} r_{3}^{2}\right)+\frac{1}{3} m_{4} l_{4}^{2}\right)+\tau_{\text {leg }}\right\}
\end{aligned}
$$

Here, $m$ is mass, $r$ is pulley radius, $\theta$ is angular deflection, $N$ is pulley teeth, and $l$ is the length of the mechanical arm.

By considering the relations, $\alpha_{1}=\alpha_{S}\left(N_{2} / N_{1}\right)$ and $\left(N_{1} / N_{2}\right)=N_{S}$, the actuator torque equation can be modified as shown in Equation (2). Here, $N_{1}: N_{2}=1: 3$. The necessary values of the parameters are presented in Table 1. Required torques at the knee joint, while the patient is in a sitting position, are identified from the study conducted by Akhtaruzzaman et al. (2019).

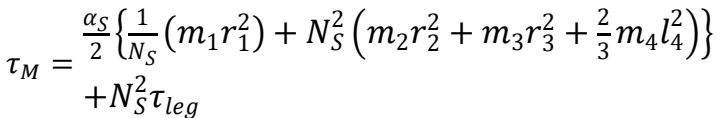

Table 1

Parameters to Calculate Required Torque of the System Actuator

\begin{tabular}{cc}
\hline \hline Parameter Symbols & Values \\
\hline$m_{1}$ & $030.0 \mathrm{~g}$ \\
$m_{2}$ & $751.0 \mathrm{~g}$ \\
$m_{3}$ & $215.0 \mathrm{~g}$ \\
$m_{4}$ & $350.0 \mathrm{~g}$ \\
$r_{1}$ & $01.50 \mathrm{~cm}$ \\
$r_{2}$ & $04.50 \mathrm{~cm}$ \\
$r_{3}$ & $03.25 \mathrm{~cm}$ \\
$l_{4}$ & $30.00 \mathrm{~cm}$ \\
$\alpha_{S}$ & $0.1300 *(180 / \pi) \mathrm{deg} / \mathrm{sec}^{2}$ \\
$N_{1}$ & 20.0 teeth \\
$N_{2}$ & 60.0 teeth \\
$\tau_{\text {leg }}$ & $\left\{895.1 \mathrm{~N} . \mathrm{cm}\right.$ for $\theta_{1}=0^{\circ}$ \\
$300.0 \mathrm{~N} . \mathrm{cm}$ for $\theta_{1}=65^{\circ}$ \\
\hline \hline
\end{tabular}

Required torque of the system actuator is calculated as $100.4 \mathrm{~N} . \mathrm{cm}$ for knee joint torque as $895.1 \mathrm{~N} . \mathrm{cm}$ at full extension of the knee. For the $25^{\circ}$ position of knee joint (knee joint torque is $300.0 \mathrm{~N} . \mathrm{cm}$ ), the required torque of the system actuator is determined as $034.3 \mathrm{~N} . \mathrm{cm}$. By considering the safety factor as $S_{f}=1.5$, calculated required torques are presented in Equation (3).

$\tau_{m}= \begin{cases}\left(\tau_{M} \times s_{f}\right) \approx 150.0 \mathrm{~N} . \mathrm{cm} & \text { for } \theta_{1}=90^{\circ} \\ \left(\tau_{M} \times s_{f}\right) \approx 050.0 \mathrm{~N} . \mathrm{cm} & \text { for } \theta_{1}=25^{\circ}\end{cases}$

\section{System Dynamics}

The conceptual Electro-mechanical model of the system actuator is presented in Figure 3. Here $\tau_{m}$ is rotor torque produced by the applied current $(i(t))$ from $V$ DC source. The $\tau_{m}$ is proportional to its magnitude. Effective inertia of armature is presented by $I_{m}$. Angular deflection $(\theta(t))$ of the rotor produces back Electromotive Force (EMF) $\left(E_{b}(t)\right)$ which is proportional to rotor angular velocity $(d \theta(t) /$ $d(t)=\dot{\theta}(t))$. Input-output ratio of gearhead is presented as, $\left(N_{m}: N_{L}=1: 10\right)$. The friction force of the gearhead module is zero $\left(\tau_{f_{m}}=0\right)$. The actuator module is connected with a switching module which is controlled by the control signals through Pulse Width Modulation (PWM) module.

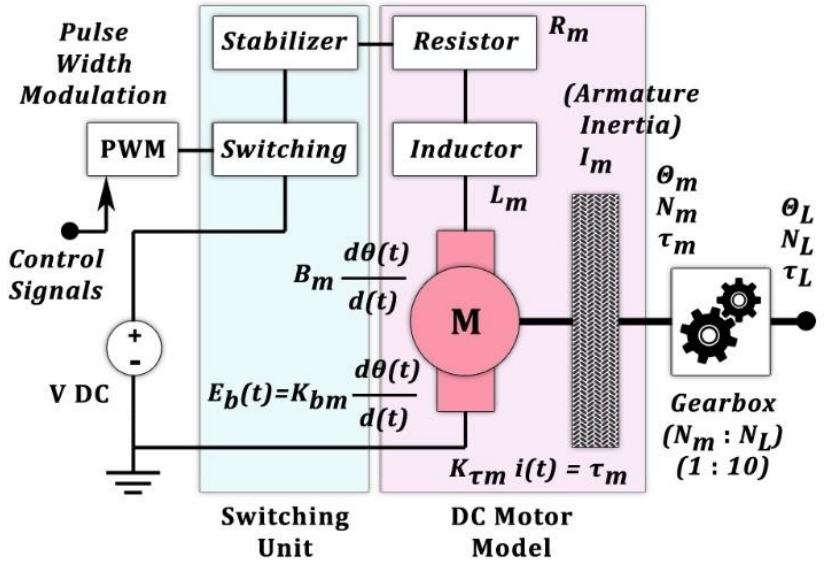

Figure 3: Conceptual Electro-mechanical model of DC Motor

Based on the characteristics of this electro-mechanical module, two differential equations can be presented as shown in Equation (4). In the equation, the constant parameters are, coil resistance $\left(R_{m}\right)$, inductance $\left(L_{m}\right)$, torque constant $\left(K_{\tau_{m}}\right)$, and back $\operatorname{EMF}\left(K_{b_{m}}\right)$. Armature inertia, viscous friction, armature load, and external load are presented by $I_{m}, B_{m}, \tau_{m}$ and $\tau_{L}$, respectively.

$\left.\begin{array}{l}L_{m} \frac{d i(t)}{d t}+K_{b_{m}} \frac{d \theta_{m}(t)}{d t}+R_{m} i(t)-v_{m}(t)=0 \\ I_{m} \frac{d^{2} \theta_{m}(t)}{d t^{2}}+B_{m} \frac{d \theta_{m}(t)}{d t}+\frac{N_{m}}{N_{L}}\left(\tau_{L}\right)-K_{\tau_{m}} i(t)=0\end{array}\right\}$

Now, from the free-body diagram in Figure 2, the external load $\left(\tau_{L}\right)$ can be formulated, as shown in Equation (5).

$\tau_{L}=\left(I_{1}+\left(\frac{N_{1}}{N_{2}}\right)^{2}\left(I_{2}+I_{3}+I_{4}+I_{l e g}\right)\right) \frac{d^{2} \theta_{1}(t)}{d t^{2}}$

Now by replacing $\tau_{L}$ in the second part of Equation (4), Equation (6) can be formulated which is the necessary differential equation of the proposed system. Here, $\theta_{L}=\theta_{1}$, $N_{L}=N_{1}$, and $N_{m} / N_{L}=\theta_{1} /_{\theta_{m}}$ are applied to establish a relation with control parameter $\theta_{1}$. Necessary parameter definitions are presented in Equation (7). Table 2 presents the necessary parameter values of the system dynamic model.

$\left.\begin{array}{l}L_{m} \frac{d i(t)}{d t}+K_{b_{m}} N_{R_{m}} \frac{d \theta_{1}(t)}{d t}+R_{m} i(t)-v_{m}(t)=0 \\ I_{E Q} \frac{d^{2} \theta_{1}(t)}{d t^{2}}+B_{E Q} \frac{d \theta_{1}(t)}{d t}-K_{\tau_{m}} i(t)=0\end{array}\right\}$

$I_{E Q}=N_{R_{m}} I_{m}+\frac{1}{N_{R_{m}}}\left(I_{1}+N_{R}^{2}\left(I_{2}+I_{3}+I_{4}+I_{\text {leg }}\right)\right)$

$B_{E Q}=N_{R_{m}} B_{m}$

$N_{R}=\frac{N_{1}}{N_{2}}$

$N_{R_{m}}=\frac{N_{L}}{N_{m}}$

$I_{1}=\frac{1}{2} m_{1} r_{1}^{2}$

$I_{2}=\frac{1}{2} m_{2} r_{2}^{2}$

$I_{3}=\frac{1}{2} m_{3} r_{3}^{2}$

$I_{4}=\frac{1}{3} m_{4} l_{4}^{2}$

$I_{\text {leg }}=m_{\text {leg }} l_{\text {com }}^{2}$ 
Table 2

Necessary Parameters of the System

\begin{tabular}{cc}
\hline \hline Parameter Symbols & Values \\
\hline$K_{\tau_{m}}$ & $1500^{\mathrm{N} . \mathrm{cm} / \mathrm{amp}}$ \\
$K_{b_{m}}$ & $0.125^{\mathrm{v}} / \mathrm{rad} . \mathrm{sec}$ \\
$R_{m}$ & $5 \Omega$ \\
$L_{m}$ & $0.055 \mathrm{H}$ \\
$B_{m}$ & $034.8 \mathrm{N.cm} / \mathrm{rad} . \mathrm{sec}$ \\
$I_{m}$ & $0.0068 \mathrm{~g} / \mathrm{cm}^{2}$ \\
$m_{\text {leg }}$ & $4030.0 \mathrm{~g}$ \\
$l_{\text {com }}$ & $12.92 \mathrm{~cm}$ \\
$N_{m}$ & 10 \\
$N_{L}$ & 100 \\
\hline \hline
\end{tabular}

\section{System Transfer Functions (TF)}

The first part of Equation (6) is the electrical circuit dynamics, and the second part is the mechanical dynamics. Now by applying Laplace Transform (LT), the differential equation (in time domain) can be transformed into an algebraic equation (in frequency domain) to find out the solutions and present as output-over-input (transfer function of the system). After applying LT, the new form of Equation (6) is presented in Equation (8) where the mechanical dynamic equation is rewritten into two separate formats, one is based on angular position $\left(\theta_{1}\right.$ for position control) and the other one is based on angular velocity $\left(\dot{\theta}_{1}\right.$ for velocity control).

$\left.\begin{array}{l}s L_{m} I(s)+s K_{b_{m}} N_{R_{m}} \theta_{1}(s)+R_{m} I(s)-v_{m}(s)=0 \\ s^{2} I_{E Q} \theta_{1}(s)+s B_{E Q} \theta_{1}(s)-K_{\tau_{m}} I(s)=0 \\ s I_{E Q} \dot{\theta_{1}}(s)+B_{E Q} \dot{\theta_{1}}(s)-K_{\tau_{m}} I(s)=0\end{array}\right\}$

From the above equation, necessary sub equations can be determined for $\left(V_{m}(s)-s K_{b_{m}} \theta(s)\right)$ from electrical dynamics and $I(s)$ from two equations of mechanical dynamics. Now replacing $I(s)$ in the electrical dynamic equation, two TFs can be determined as presented in Equation (9) and (10). The TF in Equation (9) is for position control and the TF in Equation (10) is for velocity control.

$$
\begin{aligned}
& \frac{\theta_{1}(s)}{V_{m}(s)}=\frac{K_{\tau_{m}}}{s^{3} I_{E Q} L_{m}+s^{2}\left(I_{E Q} R_{m}+B_{E Q} L_{m}\right)+s\left(B_{E Q} R_{m}+K_{b_{m}} K_{\tau_{m}} N_{R m}\right)} \\
& \frac{\dot{\theta}_{1}(s)}{V_{m}(s)}=\frac{K_{\tau_{m}}}{s^{2} I_{E Q} L_{m}+s\left(I_{E Q} R_{m}+B_{E Q} L_{m}\right)+\left(B_{E Q} R_{m}+K_{b_{m}} K_{\tau_{m}} N_{R_{m}}\right)}
\end{aligned}
$$

\section{CONTROL ENGINEERING}

The motion of the system arm is operated by an input voltage $V_{m}$. To control the arm position and motion velocity, two PID compensators $\left(C_{\theta}\right.$ and $\left.C_{\dot{\theta}}\right)$ need to be designed. In the manual PID tuning, $K_{P}$ is increased to minimize rise time while $K_{I}=K_{D}=0$. Then, for minimizing any steadystate error (SSE), $K_{I}$ is increased. Finally, for ensuring faster settling time, $K_{D}$ is increased (reduce overshoot). In this paper, MATLAB SIMULINK based tuning is considered.
To design a robot-assisted rehabilitation system, it is necessary to define the limits of performance control parameters (PCP) values which are determined from the literatures presented in this paper. Table 3 presents the various results identified from the literatures. To design a robust rehabilitation robotic device, Percent of Overshoot (\%OS), Rise time (RT), Settling time (ST), and Steady-state error (SSE) must be as minimum as possible. Thus, the average values of the identified PCP parameters, presented in Table 3, are considered in designing the position-PID compensator. The PCP limits are chosen as, $(0.00<$ $\% O S<12.00),(0.00<R T<01.20$ sec. $), \quad(0.00<$ $S T<3.00$ sec. $)$, and $(0.00<S S E<0.11)$.

Table 3

Selection of Performance Control Parameters (PCP)

\begin{tabular}{|c|c|c|c|c|c|}
\hline \multirow[b]{2}{*}{ Ref. } & \multirow[b]{2}{*}{$\begin{array}{c}\text { Control } \\
\text { Types }\end{array}$} & \multicolumn{4}{|c|}{ PCP } \\
\hline & & $\% O S$ & $\begin{array}{c}\text { RT } \\
\text { (sec.) }\end{array}$ & $\begin{array}{c}\text { ST } \\
\text { (sec.) }\end{array}$ & SSE \\
\hline \multirow{3}{*}{$\begin{array}{c}\text { Joyo et al. } \\
(2019) \\
\text { [joint-1] }\end{array}$} & PSO-PID & 17.225 & 00.095 & 00.924 & -- \\
\hline & ABC-PID & 01.836 & 00.275 & 00.413 & -- \\
\hline & ZN-PID & 51.417 & 00.282 & 04.537 & -- \\
\hline \multirow{3}{*}{$\begin{array}{c}\text { Yoyo et al. } \\
\text { (2019) } \\
\text { [joint-2] }\end{array}$} & PSO-PID & 00.000 & 00.421 & 00.652 & -- \\
\hline & ABC-PID & 05.101 & 00.022 & 00.095 & -- \\
\hline & ZN-PID & 10.284 & 00.028 & 01.400 & -- \\
\hline \multirow{2}{*}{$\begin{array}{l}\text { Ali et al. } \\
\text { (2018) }\end{array}$} & PID & 07.400 & 00.400 & 02.380 & -- \\
\hline & $\begin{array}{l}\text { Fuzzy- } \\
\text { PID }\end{array}$ & 07.000 & 00.510 & 03.500 & -- \\
\hline \multirow{4}{*}{$\begin{array}{l}\text { Faizura et } \\
\text { al. }(2020)\end{array}$} & PID & 38.000 & 02.130 & 08.250 & 00.380 \\
\hline & Fuzzy & 02.000 & 02.800 & 07.250 & 00.020 \\
\hline & $\begin{array}{l}\text { Fuzzy- } \\
\text { PID }\end{array}$ & 00.000 & 04.980 & 06.500 & 00.000 \\
\hline & PID-PSO & 04.000 & 02.070 & 05.300 & 00.040 \\
\hline \multicolumn{2}{|c|}{ Average values } & 12.022 & 01.168 & 03.433 & 00.110 \\
\hline
\end{tabular}
to design position-PID

\section{A. Compensator for Position Control $\left(C_{\theta}\right)$}

MATLAB Simulink block-diagram for position control $\left(C_{\theta}\right)$ PID compensator is presented in Figure 4. Position error is calculated by subtracting the position feedback from desired position and feed to the position-PID. The PID compensator generates a necessary control signal and passes it into the system plant. Within the range of PCP limits, in the first tuning the values of $K_{P}, K_{I}$, and $K_{D}$ are selected as 0.562 , 0.009 , and 0.304 , respectively. The resultant system responses are presented in Figure 5 where the position responses of the system are $\% O S \approx 9.90, R T \approx 1.00 \mathrm{sec}$., $S T \approx 3.00 \mathrm{sec}$., and $S S E \approx 0.06$. Though $\mathrm{PCP}$ values of the system are in the selected range, the velocity response is in under-damp condition. Thus, the PID of $C_{\theta}$ needs to be tuned more to get a robust response of the system. Table 4 presents the PCP values of system responses for four different tunings of $C_{\theta}$. Among the various responses, the best performance is observed for $K_{P}=04.530, K_{I}=$ 00.567 , and $K_{D}=04.033$. Under this condition, the simulated response is presented in Figure 6. 


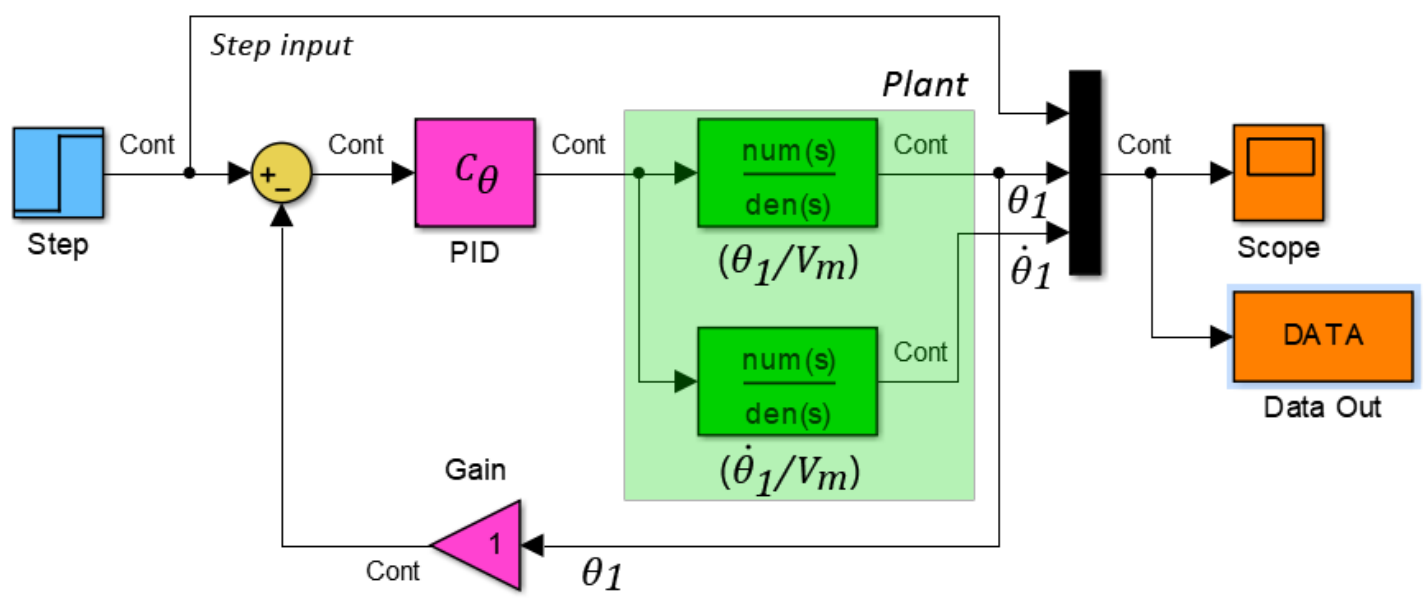

Figure 4: Control architecture (MATLAB Simulink diagram) in designing $C_{\theta}$ PID Compensator

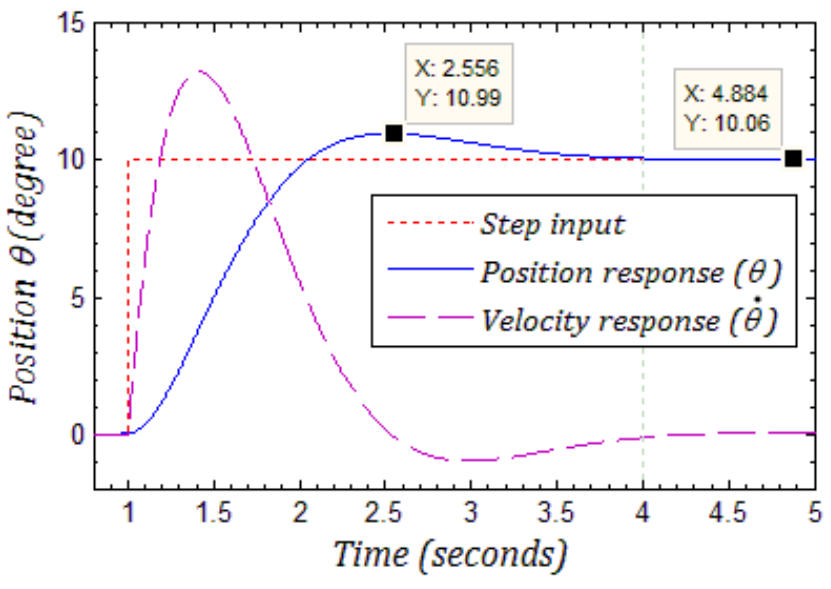

Figure 5: System response for PID compensator $C_{\theta}$ where $K_{P}=0.562, K_{I}=0.009$, and $K_{D}=0.304$

According to the graph (Figure 6), no overshoot is observed for the position response $(\% O S=00.00)$, the steady-state error is observed as a minimum ( $E S S=$ $0.050)$. The system also shows the faster rise time and faster settling time $(R T=00.240 \mathrm{sec}$. and $S T=$ $00.300 \mathrm{sec}$.).

Table 4

Various PCP values for different tuning of position-PID $\left(C_{\theta}\right)$

\begin{tabular}{|c|c|c|c|c|c|}
\hline \multirow{2}{*}{$\stackrel{\Xi}{\Xi}$} & \multirow{2}{*}{$\begin{array}{c}\text { PID } \\
\text { Values }\end{array}$} & \multicolumn{4}{|c|}{ PCP } \\
\hline & & $\% 0 S$ & $\begin{array}{c}\text { RT } \\
\text { (sec.) }\end{array}$ & $\begin{array}{c}\text { ST } \\
\text { (sec.) }\end{array}$ & SSE \\
\hline $1^{\text {st }}$ & $\begin{array}{l}K_{P}=00.562 \\
K_{I}=00.009 \\
K_{D}=00.304\end{array}$ & 09.900 & 01.000 & 03.000 & 00.060 \\
\hline $2^{\text {nd }}$ & $\begin{array}{l}K_{P}=01.099 \\
K_{I}=00.049 \\
K_{D}=01.109\end{array}$ & 00.000 & 00.859 & 01.040 & 00.080 \\
\hline $3^{\text {rd }}$ & $\begin{array}{l}K_{P}=04.530 \\
K_{I}=00.567 \\
K_{D}=04.033\end{array}$ & 00.000 & 00.240 & 00.300 & 00.050 \\
\hline $4^{\text {th }}$ & $\begin{array}{l}K_{P}=52.979 \\
K_{I}=29.090 \\
K_{D}=21.437\end{array}$ & 01.300 & 00.054 & 0.277 & 00.060 \\
\hline
\end{tabular}
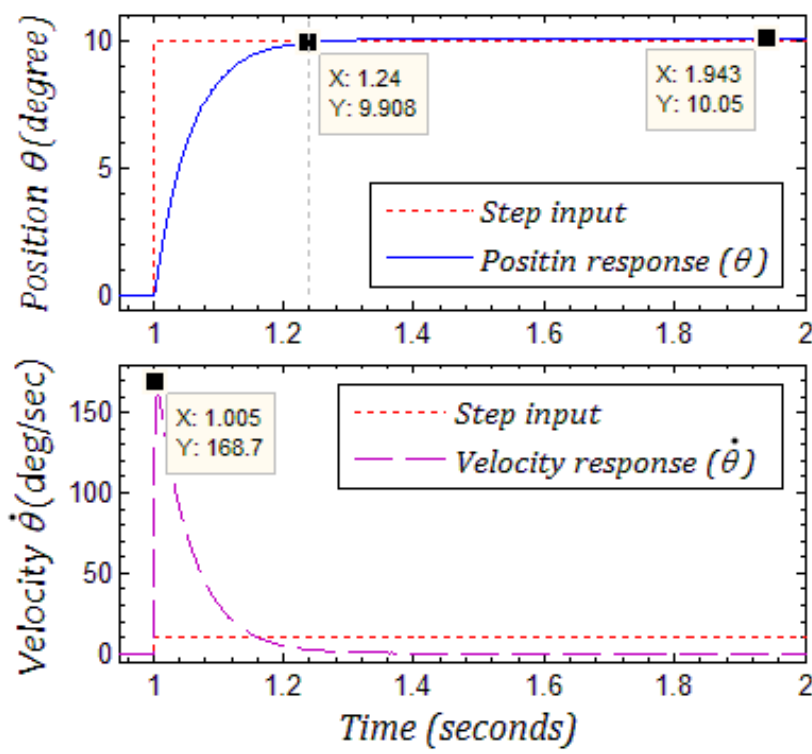

Figure 6: System response ( $3^{\text {rd }}$ tuning) for PID compensator $C_{\theta}$ where $K_{P}=4.530, K_{I}=0.567$, and $K_{D}=4.033$

\section{B. Compensator for Velocity Control $\left(C_{\dot{\theta}}\right)$}

A robot-assisted rehabilitation system must have the capability to follow a trajectory with the desired velocity. The sudden change of velocity may cause the system to unstable creating secondary injury to the targeted limbs. In Figure 6, the velocity response shows high deflection, thus it is necessary to design 2nd compensator $\left(C_{\dot{\theta}}\right)$ for velocity control. The control architecture is presented in Figure 7. Considering the chosen PCP limits, the values of $K_{P}, K_{I}$, and $K_{D}$ are tuned as $140.00,18416.00$, and 00.10 , respectively. Table 5 presents the various responses of four different trials from where the results of the 3rd trial are considered, thus selected the velocity-PID parameter values. To design the control architecture, the switching mechanism is adopted. The philosophy behind this technique is that the velocityPID will dominate to maintain the desired constant velocity during motion and the control responsibility will switch to the position-PID at the moment of the system arm reaches the desired position and maintain the desired angular state. 
Table 5

Various PCP values for different tuning of velocity-PID $\left(C_{\dot{\theta}}\right)$

\begin{tabular}{|c|c|c|c|c|c|}
\hline \multirow[b]{2}{*}{$\stackrel{巳}{\Xi}$} & \multirow[b]{2}{*}{$\begin{array}{c}\text { PID } \\
\text { Values }\end{array}$} & \multicolumn{4}{|c|}{ PCP } \\
\hline & & $\% 0 S$ & $\begin{array}{c}\mathrm{RT} \\
\text { (sec.) }\end{array}$ & $\begin{array}{c}\text { ST } \\
\text { (sec.) }\end{array}$ & SSE \\
\hline $1^{\text {st }}$ & $\begin{array}{c}K_{P}=45.00 \\
K_{I}=8516.00 \\
K_{D}=00.80\end{array}$ & 25.600 & 00.021 & 00.356 & -0.120 \\
\hline $2^{\text {nd }}$ & $\begin{array}{c}K_{P}=80.00 \\
K_{I}=18516.00 \\
K_{D}=00.20\end{array}$ & 34.700 & 00.009 & 00.069 & -0.018 \\
\hline $3^{\text {rd }}$ & $\begin{array}{c}K_{P}=140.00 \\
K_{I}=18416.00 \\
K_{D}=00.10\end{array}$ & 29.500 & 00.006 & 00.028 & -0.019 \\
\hline $4^{\text {th }}$ & $\begin{array}{c}K_{P}=180.00 \\
K_{I}=29323.00 \\
K_{D}=00.10\end{array}$ & 41.500 & & Unstable & \\
\hline
\end{tabular}

The system plant (system dynamic model) is basically a Single-Input Multi-Output (SIMO) system as both position and velocity outputs depend on the input of electric voltage $\left(V_{m}\right)$ to the system plant. The design of the control architecture reflects the parallel configuration of two compensators. Here the position and velocity errors are feed to position-PID $\left(C_{\theta}\right)$ and velocity-PID ( $\left.C_{\dot{\theta}}\right)$ compensators separately. The output of both PIDs is then summed up and feed as a single input to the system plant. To observe the system performance, the designed architecture is simulated for a constant velocity input as $10 \mathrm{deg} . / \mathrm{sec}$. while a step input is applied for position change from $0.0^{\circ}$ to $20.00^{\circ}$. At this condition, the arm must rise to its desired angle within two seconds while maintaining the desired velocity complying with the selected PCP characteristics. Figure 8 shows the simulated responses of the system and corresponding error characteristics for such input conditions.

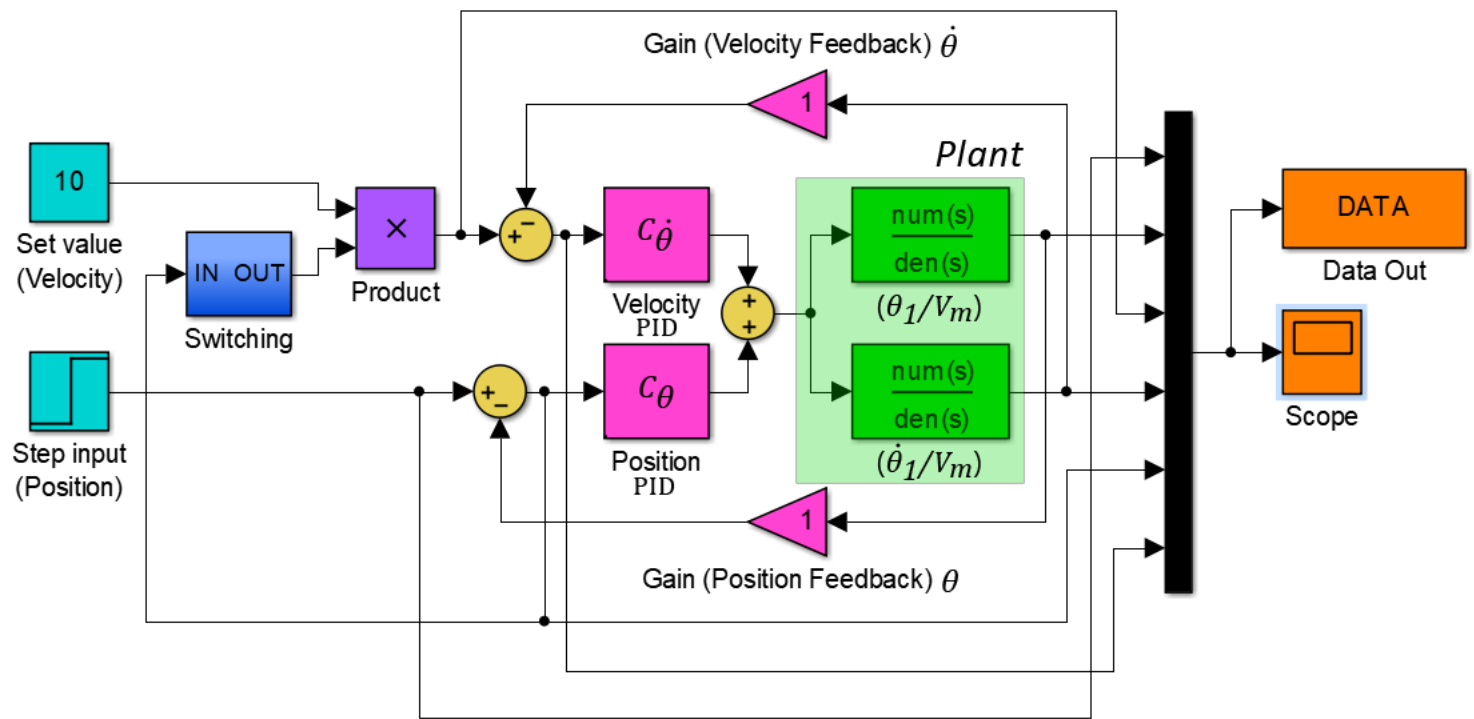

Figure 7: Control architecture (MATLAB Simulink diagram) in designing $C_{\theta}$ and $C_{\dot{\theta}}$ PID Compensators
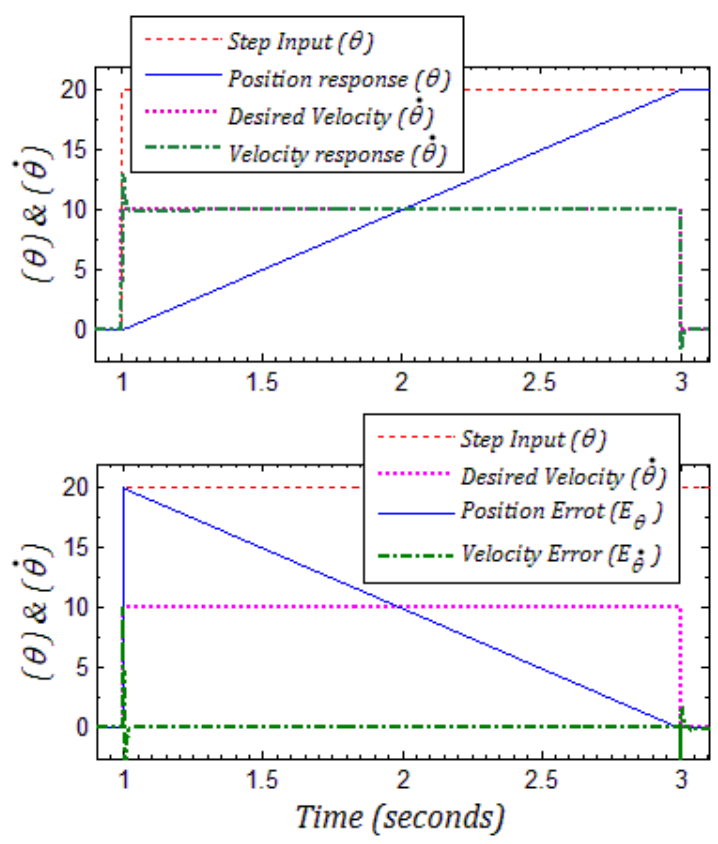

Figure 8: System responses ( $3^{\text {rd }}$ tuning) of velocity-PID $\left(C_{\dot{\theta}}\right)$

\section{RESULTS AND DISCUSSION}

Results of the designed architecture show a stable system response both in position and velocity control. The desired position and velocity of the robot arm are achieved within the desired PCP value ranges. The system is simulated for various input conditions to confirm the suitability of the designed control architecture. Figure 8 has presented the simulated results of the system for the input parameters as $0.0^{\circ}$ to $20.0^{\circ}$ motion range with a constant velocity of $10.0 \mathrm{deg} . / \mathrm{sec}$. Angle rise time satisfies the desired time for about two seconds with a smooth motion trajectory. Though some deflections are observed for velocity response at the initiation and termination of motion, the results of position control satisfy selected PCP ranges.

Figure 9 presents clear observations of velocity response and the corresponding error characteristics at the initiation of motion. The graph shows that the rise time is about $0.006 \mathrm{sec}$. with the percent of overshoot is about 29.50 . The settling time of the velocity response is around $0.028 \mathrm{sec}$. and steady-state error is almost 0.019 . The results comply with the $\mathrm{PCP}$ value ranges for position 
response, thus ensure the suitability of the designed control architecture.
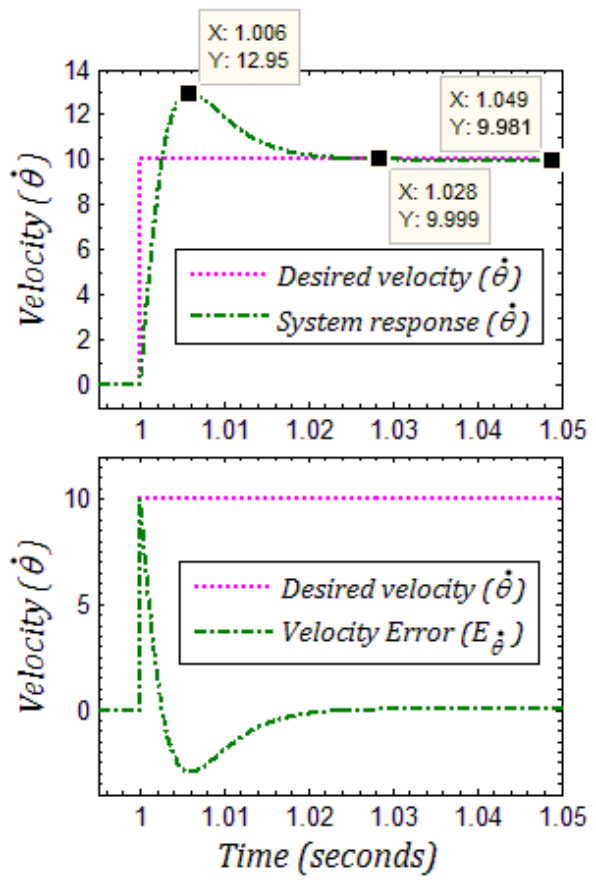

Figure 9: Velocity response and corresponding errors of the system at the initiation of motion

Motion termination occurs when the system reaches the desired angular position. At this moment, the switching is activated, and the control is switched back to the positionPID compensator to hold the arm at the desired angle. At the same time, the velocity reaches zero. Figure 10 shows the velocity response of the system at the termination of motion. The graph shows that the rise time is around $0.006 \mathrm{sec}$., settling time is about $0.027 \mathrm{sec}$., and steadystate error is 0.0037 . The percent of overshoot is detected as 16.20 . For a rising motion of the system arm, two switching conditions have occurred, one is position-PID to velocity-PID at the initiation of motion (hold at $0.0^{\circ}$ to swing) and the other is velocity-PID to position-PID at the termination of motion (swing to hold at 20.0 ). A comparison of the velocity responses in between these two switching conditions reflects that all the PCP values at motion-termination are lower than motion-initiation. This behavior explains that the system needs less energy to settle down the velocity to zero at hold condition. Opposingly, the system needs high energy at the motioninitiation state to maintain the desired velocity. A similar test with different input conditions is simulated resulting in the same behavior of the system response. The system is also tested with an external disturbance input. The disturbance is applied at the position response of the system to observe the effects on system stability in terms of position and velocity responses. Figure 11 shows the system control architecture with an Impulse Generator (IG) as an external disturbance to the position output $(\theta)$ of the plant.
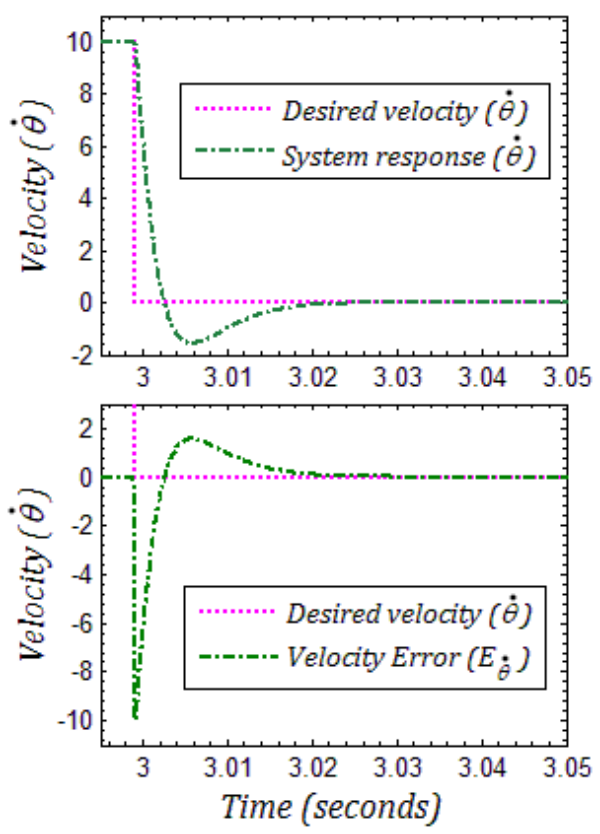

Figure 10: Velocity response and corresponding errors of the system at the termination of motion

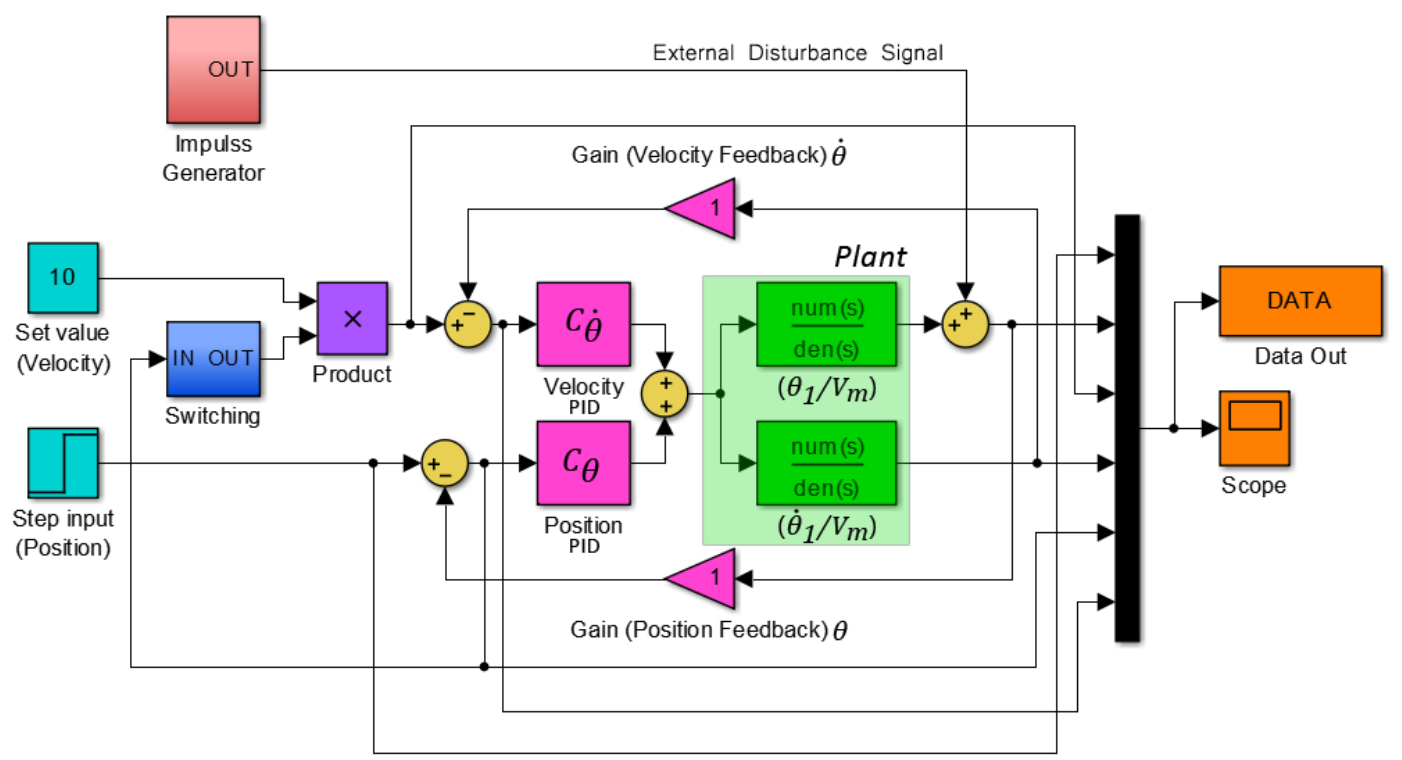

Figure 11: System control architecture with an external disturbance at the position output just before the position feedback 
The IG generates a single pulse of $0.001 \mathrm{sec}$. pulse width and $10.00^{\circ}$ amplitude. The impulse signal is added with the $\theta$ output response of the system; thus, position response reflects a sharp rise and falls at a specific time of the system operation. For the test simulation, two impulse signals are applied, i) a positive impulse during motion at $4.70 \mathrm{sec}$., and ii) a negative impulse during $45.00^{\circ}$ hold condition at $6.00 \mathrm{sec}$. Figure 12 shows the system response for the input parameters as $10.00 \mathrm{deg} . / \mathrm{sec}$. velocity and step function from $0.0^{\circ}$ to $45.00^{\circ}$.
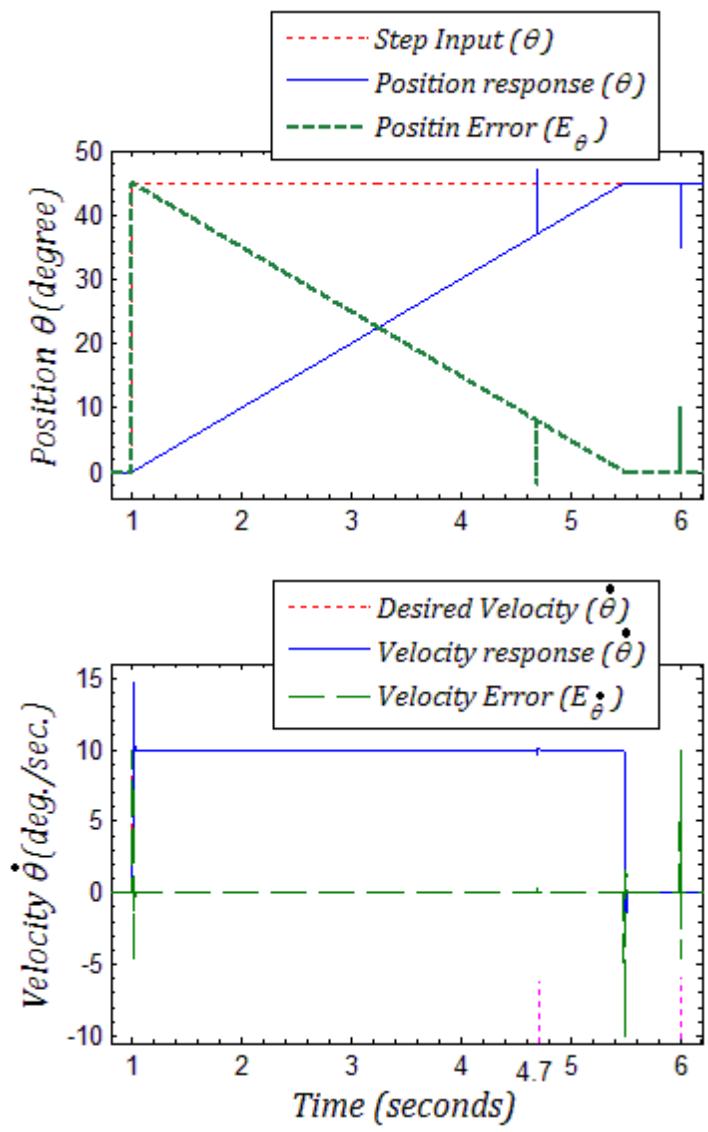

Figure 12: System position and velocity responses for Position set-point at $45.0^{\circ}$ and Velocity set-point at $10.0 \mathrm{deg} . / \mathrm{sec}$. while external disturbances are at $4.70 \mathrm{sec}$. (positive disturbance) and at $6.00 \mathrm{sec}$. (negative disturbance)

According to the above figure, the position response of the system shows a smooth transition at the initiation and termination of motion. Velocity response shows some deflections at the initiation at time $1.00 \mathrm{sec}$. and termination of the motion at $5.50 \mathrm{sec}$. The behavior is clearly presented in Figure 13 where (a) reflects velocity response with error behavior at the initiation and (b) shows velocity response with corresponding error behavior at the termination of motion. From the response graphs, the PCP values are extracted as $\% O S=47.30, R T=0.006 \mathrm{sec}$., $S T=0.033 \mathrm{sec}$. and $S S E=-0.044$ at the initiation of motion and $\% O S=15.34 ., R T=0.006 \mathrm{sec} ., S T=$ $0.031 \mathrm{sec}$, and $S S E=0.0041$ at the termination of motion. The response of the system for positive impulse disturbance at $4.70 \mathrm{sec}$. during motion and negative impulse disturbance at $6.00 \mathrm{sec}$. during the $45.00^{\circ}$ hold position are presented in Figure 14 and Figure 15, respectively. For the positive impulse during rising motion, velocity goes down to about $9.713 \mathrm{deg} . / \mathrm{sec}$. and reaches to the desired velocity $(\approx 10.00 \mathrm{deg} . / \mathrm{sec}$.$) at 4.728 \mathrm{sec}$., reflecting $S T=0.028 \mathrm{sec} ., \quad \% O S=2.787, R T=$ $0.008 \mathrm{sec}$. and $S S E=0.0030$. For the negative impulse, the desired velocity rises to its set point and falls to zero reflecting the impulse disturbance to the velocity input (Figure 15). Velocity response rises to $4.603 \mathrm{deg} . / \mathrm{sec}$. and settles down to zero by $0.022 \mathrm{sec}$. with $\% O S=5.110$, as presented in Figure 15.
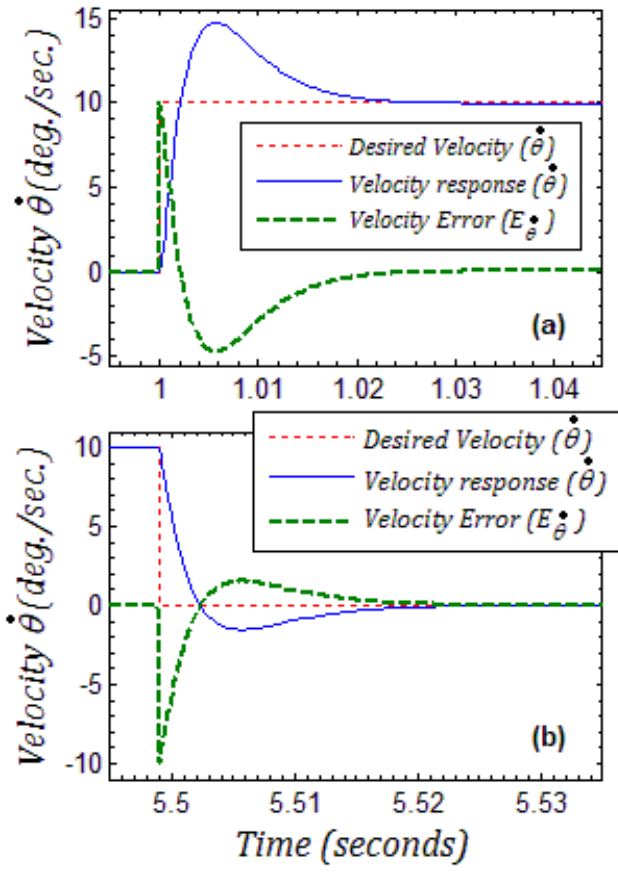

Figure 13: Velocity responses and error behaviors; (a) at motion initiation, and (b) at motion termination

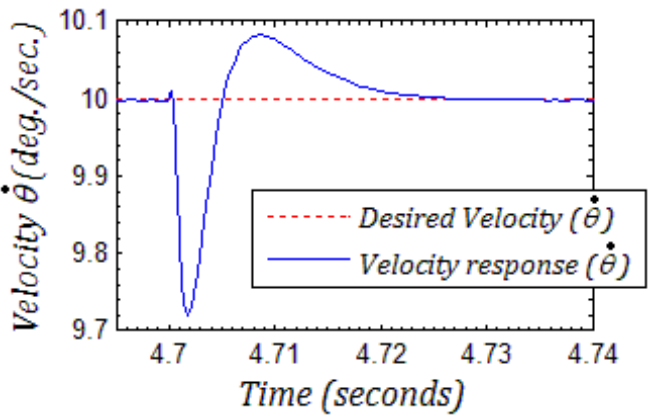

Figure 14: Velocity responses of the system for positive disturbance (position) input at $4.7 \mathrm{sec}$.

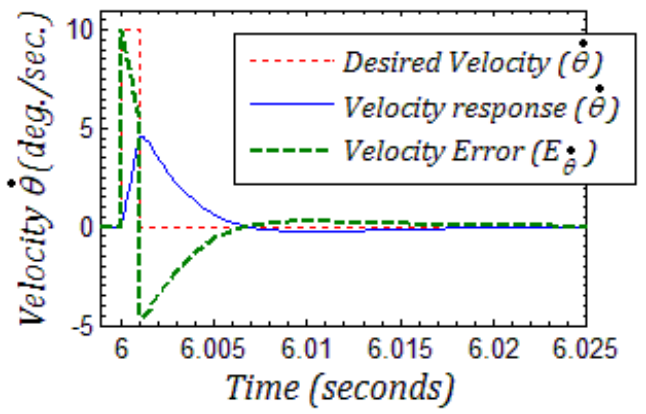

Figure 15: Velocity responses for negative disturbance (position) at $6.00 \mathrm{sec}$. while robot-arm is holding at $45^{\circ}$ 
For the impulse disturbance, system output shows a very little impact on the position $(\theta)$ response. Figure 16 presents the position response for $-10^{\circ}$ impulse at $6.00 \mathrm{sec}$. while the robot arm is in holding a position at $45.00^{\circ}$ angles. From various simulation results, it is observed that the system shows good performances while the velocity range is $0.00<\dot{\theta}<14.00 \mathrm{deg} . / \mathrm{sec}$. At $0.00 \mathrm{deg} . / \mathrm{sec}$. there is no angular motion observed at the robot arm. Conversely, the velocity greater than $14.00 \mathrm{deg} . / \mathrm{sec}$. makes the system unstable. Table 6 presents the PCP values of position and velocity responses for various input conditions.

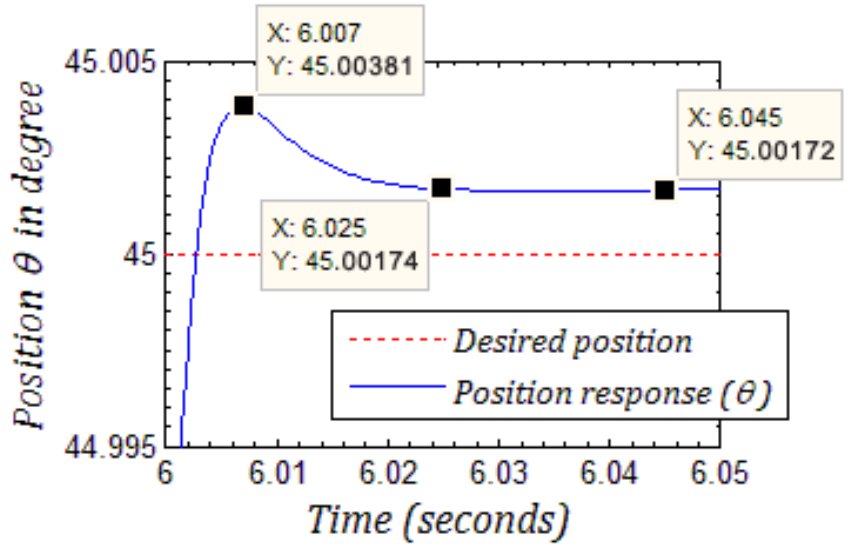

Figure 16: Position $(\theta)$ response of the system for $-10^{\circ}$ impulse disturbance at $6.00 \mathrm{sec}$. while the robot arm is holding at $45.0^{\circ}$ angle

Table 6

System PCP values of position and velocity responses for various input conditions

\begin{tabular}{|c|c|c|c|c|c|}
\hline \multirow{2}{*}{$\begin{array}{l}\text { Input } \\
\text { Conditions }\end{array}$} & \multirow[b]{2}{*}{ Outputs } & \multicolumn{4}{|c|}{ PCP Values } \\
\hline & & $\% 0 S$ & $\begin{array}{c}\text { RT } \\
\text { (sec.) }\end{array}$ & $\begin{array}{c}\text { ST } \\
\text { (sec.) }\end{array}$ & SSE \\
\hline \multirow{5}{*}{ 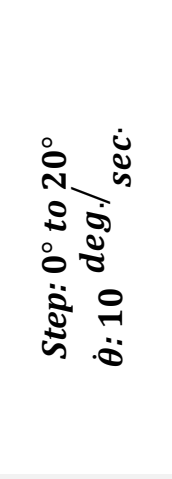 } & $\begin{array}{l}\dot{\theta} @ \text { start } \\
\text { of motion }\end{array}$ & 29.50 & 0.006 & 0.028 & 0.0190 \\
\hline & $\begin{array}{c}\dot{\theta} @ \text { end of } \\
\text { motion }\end{array}$ & 16.20 & 0.006 & 0.027 & 0.0037 \\
\hline & $\begin{array}{c}\dot{\theta} \text { for }+10^{\circ} \\
\text { impulse @ } \\
\text { motion }\end{array}$ & 19.66 & 0.009 & 0.031 & 0.0030 \\
\hline & $\begin{array}{c}\dot{\theta} \text { for }+10^{\circ} \\
\text { impulse @ } \\
20^{\circ} \text { hold }\end{array}$ & 5.405 & 0.010 & 0.022 & 0.0030 \\
\hline & $\begin{array}{c}\theta \text { for }+10^{\circ} \\
\text { impulse @ } \\
20^{\circ} \text { hold }\end{array}$ & 0.036 & 0.007 & 0.025 & 0.0016 \\
\hline \multirow{5}{*}{ 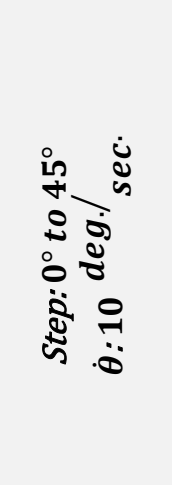 } & $\begin{array}{l}\dot{\theta} @ \text { start } \\
\text { of motion }\end{array}$ & 47.30 & 0.006 & 0.033 & 0.0440 \\
\hline & $\begin{array}{c}\dot{\theta} @ \text { end of } \\
\text { motion }\end{array}$ & 15.34 & 0.006 & 0.031 & 0.0041 \\
\hline & $\begin{array}{c}\dot{\theta} \text { for }+10^{\circ} \\
\text { impulse @ } \\
\text { motion }\end{array}$ & 2.787 & 0.008 & 0.028 & 0.0030 \\
\hline & $\begin{array}{c}\dot{\theta} \text { for }-10^{\circ} \\
\text { impulse @ } \\
45^{\circ} \text { hold }\end{array}$ & 5.110 & 0.010 & 0.022 & 0.0017 \\
\hline & $\begin{array}{c}\theta \text { for }-10^{\circ} \\
\text { impulse @ } \\
45^{\circ} \text { hold }\end{array}$ & 0.038 & 0.007 & 0.025 & 0.0017 \\
\hline
\end{tabular}

\section{CONCLUSIONS}

This paper presents dynamic modeling and simulation of a robot-assisted rehabilitation system for knee joint RoM exercise. The paper describes a control architecture for position and velocity control of a 1-DoF robotic arm attached with a mechanical chair. The viability of the proposed control architecture is verified by performing simulations for various input parameter sets. The main goal is to provide robot-assisted motion exercise to the knee joint ensuring a smooth and continuous motion pattern.

The designed model basically reflects a SIMO system as it has one input and two output channels. From the dynamic model of the system, transfer functions are derived to design the Plant model. The control architecture is designed with two PIDs as parallel compensators, positionPID $\left(C_{\theta}\right)$ for position control and velocity-PID $\left(C_{\dot{\theta}}\right)$ for velocity control. A switching mechanism is adopted to transfer the control from one PID to another at the transition moments, hold to swing transition (motion initiation) and swing to hold transition (motion termination). The position-PID is designed by determining some PCP parameter values based on the literatures studied and presented in this paper. Then velocity-PID is designed through iterative technique. In this case, MATLAB based tuning method is followed and PID parameter values are selected after some comparative analysis among the results of several iterations. Finally, several simulation tests were conducted to observe the PCP responses of the system in terms of position $(\theta)$ and velocity $(\dot{\theta})$ responses of the system.

Responses of the system show impressive results as the PCP values are in the selected ranges for position response. The results show, for the position response, the $\% O S<$ $12.00, R T<1.00 \mathrm{sec}$., $S T<3.00 \mathrm{sec}$., and $S S E<0.100$. Velocity responses also present very low rise-time, settling-time, and steady-state error with the $\% O S$ in between 0.036 and 47.50. Although, experiments show that the velocity range for the smooth operation of the system is $1.00 \mathrm{deg} . / \mathrm{sec}$. to $13.00 \mathrm{deg} . / \mathrm{sec}$., highest recommended velocity is $10.00 \mathrm{deg} . / \mathrm{sec}$. Velocity higher than this limit will cause the system unstable.

Experimental results have ensured the viability of the system for implementation and practical use. Though only position and velocity control are not enough for a ManMachine cooperative robot, this experiment presents the initial step in designing such a machine. In this COVID-19 situation, this kind of automatic rehabilitation system is in high demand for clinical therapeutic exercise to ensure the social distance during providing the services to the patients. Automated robot-assisted therapy also could be beneficial for military rehabilitation. The system can be improved by using PID improving techniques and applying several control mechanisms like Passivity based control (PBC), Linear quadratic regulator (LQR), Linear quadratic Gaussian (LQG), Force control, Impedance control, Reinforcement learning, Fuzzy intelligent control, Artificial Neural Network (ANN), and so on (Akhtaruzzaman et al., 2009; Akhtaruzzaman \& Shafie, 2010; Akdogan \& Adli. 2011). 


\section{ACKNOWLEDGEMENTS}

The authors would like to express their gratitude to the Ministry of Education, Bangladesh, Ministry of Higher Education (MOHE), Malaysia; the department of Computer Science and Engineering, Military Institute of Science and Technology (MIST), Bangladesh; and the department of Mechatronics Engineering, Kulliyyah of Engineering, International Islamic University Malaysia (IIUM), Malaysia. The authors also express their appreciation to the R\&D (Robotics) Section, DREAM Robotics Ltd., Dhaka, Bangladesh, and thankful to the editors and anonymous reviewers for providing insightful suggestions and comments to improve the manuscript.

\section{REFERENCES}

Abdezadeh, S., Saadi, D., Tohidirad, Y., Rashidy, R., \& Aliabadi, Z. S. (2016). Hardware Board Design and Simulation of Lower Limb Rehabilitation Robot. Majlesi Journal of Mechatronic Systems (MJMS), 5(3), 1-10.

Akdogan E. and Adli M. A. (2011). The design and control of a therapeutic exercise robot for lower limb rehabilitation: Physiotherabot. Mechatronics, Elsevier Ltd., 21, 509-522.

Akhtaruzzaman, M., \& Shafie, A. A. (2010, August 4-7). Modeling and Control of a Rotary Inverted Pendulum Using Various Methods, Comparative Assessment and Result Analysis. Proceedings of the 2010 IEEE International Conference on Mechatronics and Automation, Xi'an, China, 1342-1347.

Akhtaruzzaman, M., Akmeliawati, R., \& Yee, T. W. (2009, December 28 - 30). Modeling and Control of a Multi degree of Freedom Flexible Joint Manipulator. Second International Conference on Computer and Electrical Engineering, Dubai, UAE. (pp. 249-254).

Akhtaruzzaman, M., Shafie, A. A., Khan, M. R., \& Rahman, M. M. (2019, December 20-22). Knee Joint Kinesiology: A Study on Human Knee Joint Mechanics. $4^{\text {th }}$ International Conference on Electrical Information and Communication Technology (EICT). Khulna, Bangladesh.

Ali, A., Ahmed, S. F., Kadir, K. A., Joyo, M. K., \& Yarooq, R. N. S. (2018, May 11-12). Fuzzy PID controller for upper limb rehabilitation robotic system. 2018 IEEE International Conference on Innovative Research and Development (ICIRD), Bangkok, Thailand, (pp. 1-5), doi: 10.1109/ICIRD.2018.8376291.

Bradley, D., Marquez, C., Hawley, M., Brownsell, S., Enderby, P., \& Mawson, S. (2009). NeXOS - the design, development, and evaluation of a rehabilitation system for the lower limbs. Mechatronics, 19, 247-257.

Faizura, W. T. W., Luqman, M. Z. M., Hafiz, O. M., Naim, M. S., Armin, S. A., \& Irraivan, E. (2020). Control Techniques of
Multi-Fingered Hand for Rehabilitation. Journal of Physics: Conference Series, 1532, 012026. doi:10.1088/1742$6596 / 1532 / 1 / 012026$

Huang, Y., Nam, C., Li, W., Rong, W., Xie, Y., Liu, Y., Qian, Q., \& $\mathrm{Hu}, \mathrm{X}$. (2019). A comparison of the rehabilitation effectiveness of neuromuscular electrical stimulation robotic hand training and pure robotic hand training after stroke: A randomized controlled trial. Biomedical Signal Processing and Control, Elsevier Ltd., 56, 1-10.

Hussain, S., Xie, S. Q., \& Jamwal, P. K. (2013). Control of a robotic orthosis for gait rehabilitation. Robotics and Autonomous Systems, Elsevier B.V., 61, 911-919.

Joyo, M. K., Raza, Y., Ahmed, S. F., Billah, M. M., Kadir, K., Naidu, K., ... Mohd Yusof, Z. (2019). Optimized Proportional-Integral-Derivative Controller for Upper Limb Rehabilitation Robot. Electronics, 8(8), 826. doi:10.3390/electronics 8080826

Kimmig, R., Verheijen, R. H. M., Rudnicki, M., \& SERGS Council. (2020). Robot assisted surgery during the COVID19 pandemic, especially for gynecological cancer: a statement of the Society of European Robotic Gynaecological Surgery (SERGS). J Gynecol Oncol, 31(3). doi: 10.3802/jgo.2020.31.e59

Lee, M., Sung, D. J., Lee, J., Oh, I., Kim, S., Kim, S., \& Kim, J. (2016). Enhanced knee joint function due to accelerated rehabilitation exercise after anterior cruciate ligament reconstruction surgery in Korean male high school soccer players. Journal of Exercise Rehabilitation, 12(1), 29-36.

Lerner, Z. F., Damiano, D. L., Park, H. S., Gravunder, A. J., \& Bulea, T. C. (2016). A Robotic Exoskeleton for Treatment of Crouch Gait in Children with Cerebral Palsy: Design and Initial Application. IEEE Transactions on Neural System \& Rehabilitation Engineering. 99, 1-10. doi: 10.1109/TNSRE.2016.2595501.

Moughamir, S., Zaytoon, J., Manamanni, N., \& Afilal, L. (2002). A system approach for control development of lower limbs training machines. Control Eng. Pract., 10, 287-299.

Shi, D., Zhang, W., Zhang, W., \& Ding, X. (2019). A Review on Lower Limb Rehabilitation Exoskeleton Robots. Chin. J. Mech. Eng. 32(74), 1-11, https://doi.org/10.1186/s10033019-0389-8

Yang, G. Z., Nelson, B. J., Murphy, R. R., Choset, H., Christensen, H., Collins, S. H., Dario, P., Goldberg, K., Ikuta, K., Jacobstein, N., Kragic, D., Taylor, R. H., \& McNutt, M. (2020). Combating COVID-19-The role of robotics in managing public health and infectious diseases, Science Robotics, 5(40), eabb5589, 1-2.

Zeng, Z., Chen, P. J., \& Lew, A. A. (2020). From hightouch to high-tech: COVID-19 drives robotics adoption. Tourism Geographies. 22(3), 724-734, doi: $10.1080 / 14616688.2020 .1762118$ 